
October 1937

\title{
ESTIMATION OF AMINO NITROGEN IN INSOLUBLE PROTEINS
}

\author{
By Henry A. Rutherford, Milton Harris, and Arthur L. Smith ${ }^{1}$
}

\section{ABSTRACT}

An apparatus is described for determining the rate of evolution of nitrogen from proteins and other amino compounds during treatment with nitrous acid. Examination of the rate curves of a number of proteins indicates that there is a primary reaction with a relatively rapid evolution of nitrogen followed by a secondary reaction with a much slower evolution of nitrogen in which the rate is approximately constant. Extrapolation of the straight-line portions of the curves to zero time gives values which appear to be good estimates of the aminonitrogen contents of the proteins.

\section{CONTENTS}

I. Introduction

II. Apparatus and technique of operation _...

III. Results and discussion .

1. Decomposition of nitrous acid _................... 470

2. Estimation of amino nitrogen

IV. Summary

V. References.

\section{INTRODUCTION}

The basic amino acids, arginine, lysine, and histidine, which are of primary importance in proteins appear to be held in the protein chains by peptide linkages involving their carboxyl and $\alpha$-amino groups. Presumably, the remaining basic groups are free in the native protein and as a result, they have been related to the combining of various proteins with acids, dyes, and tannins. Completely satisfactory conclusions on the nature of such combinations have not been obtained because of the lack of suitable methods for the quantitative estimation of the free-amino groups in proteins and especially those in insoluble proteins.

The Van Slyke method $[1]^{2}$ which has been used for the determination of amino nitrogen in solutions of amino acids, peptides, etc., has limitations which have frequently been discussed [2, 3]. Its application to proteins, and more especially insoluble proteins, is further limited because of the difficulty of preparing solutions of these materials without chemical degradation.

1 Research Associates at the National Bureau of Standards, representing the American Association of Textile Chemists and Colorists. This work was aided by grants from the Textile Foundation, Inc., the Chemical Foundation, Ine., and the Eavenson and Levering Co.

2 Numbers in brackets refer to the references at the end of the paper. 
In a previous investigation, Kanagy and Harris [4] avoided such degradation by working with suspensions of powdered wool and collagen. It was shown that when these proteins are treated with nitrous acid, increasing amounts of nitrogen are evolved with increasing duration of treatment. The amount of nitrogen evolved in any arbitrary length of time does not necessarily represent the aminonitrogen content of the protein in question. The rate of evolution of

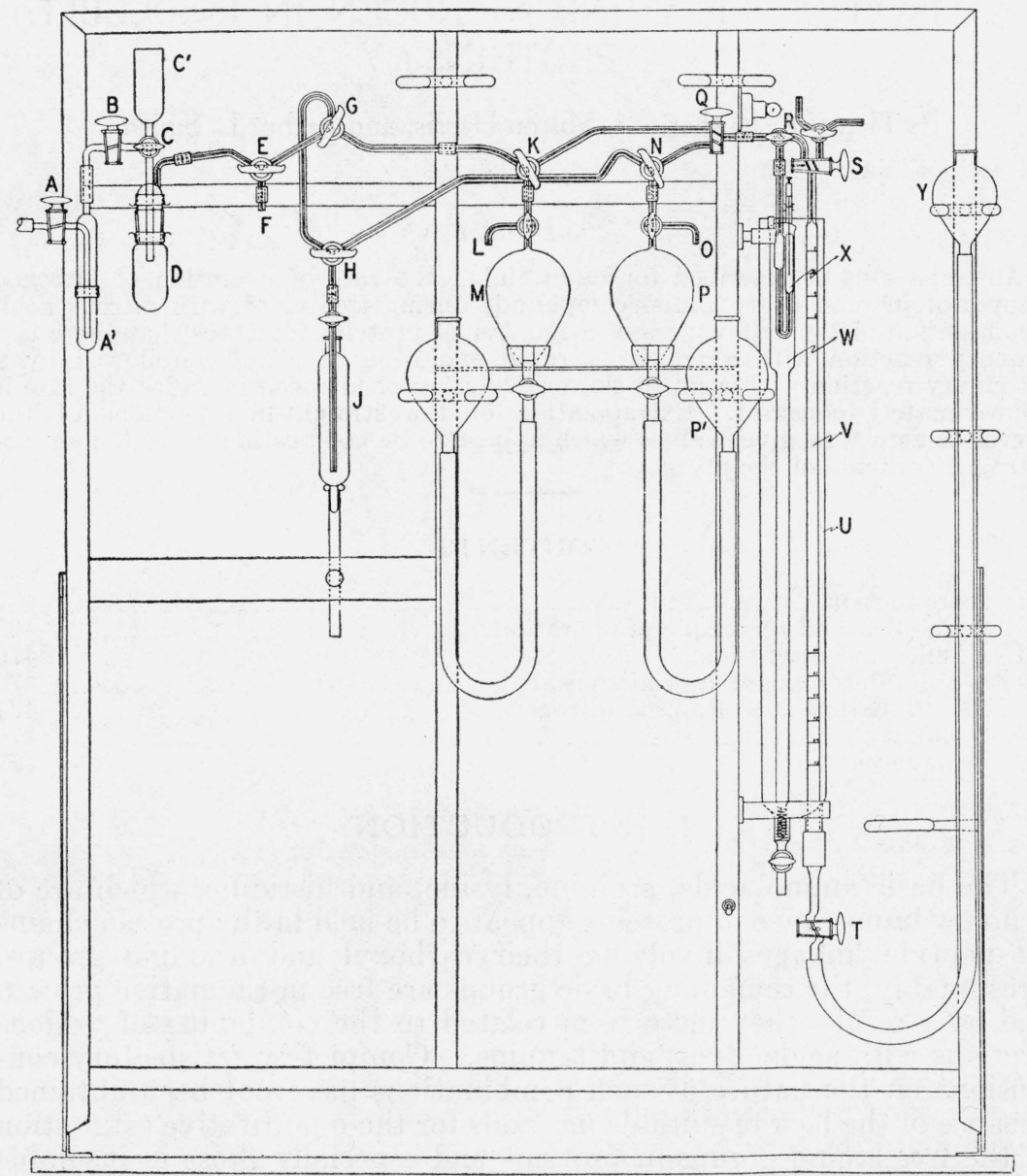

FIGURE 1.-Apparatus for determining the rate of evolution of nitrogen from proteins and other amino compounds during treatment with nitrous acid.

nitrogen from the protein, however, appeared to be significant since it indicated a primary and a secondary reaction.

The method previously employed for the determination of the rate of evolution of nitrogen was time-consuming, since a Van Slyke apparatus was used, which necessitated a separate determination for each period of time. In addition, it was difficult to prepare sufficiently uniform suspensions to assure the addition of an accurately known amount of protein for each determination. In order to 
eliminate these objections, an apparatus which requires only one sample to obtain a curve which represents the rate of evolution of nitrogen, was developed. A description of the apparatus and a number of preliminary results obtained with it are reported in the present paper.

\section{APPARATUS AND TECHNIQUE OF OPERATION}

The apparatus which was developed for this investigation is shown in figure 1. An excellent, detailed description of the construction, assembly, and manipulation of the distributor $E G K Q N H$, the bubbling pipette $J$, the water jacket $U$, the manometer $X$, the compensator $W$, and the burette $V$ is given by Shepherd [5] in a comprehensive paper on apparatus for the analysis of gas mixtures.

The bubbling pipette $J$ is filled with a saturated solution of potassium permanganate, approximately $0.5 \mathrm{~N}$ with respect to potassium hydroxide. The absorption bulb $P$, which has a capacity of $500 \mathrm{ml}$, contains $300 \mathrm{ml}$ of a potassium hydroxide solution ${ }^{3}$ (prepared by adding 3 volumes of water to 5 volumes of a saturated solution of potassium hydroxide), over mercury. The sampling bulb $M$ is filled with mercury to stopcock $K$. The distributor, and the arm of the manometer $X$ connected thereto, are filled with oxygen-free nitrogen [5]. The burette $V$ has a capacity of $25 \mathrm{ml}$ and is calibrated to 0.05 ml. Readings are readily estimated to $0.01 \mathrm{ml}$. The leveling bulb $Y$ contains enough mercury to completely fill the burette and leave an excess within the bulb.

At the beginning of an analysis the entire distributor as well as approximately $10 \mathrm{ml}$ of the burette is filled with nitrogen [5]. The alkaline permanganate solution in $J$ is adjusted to the etch-marks on the capillary stems, the mercury in $M$ to stopcock $K$, and the potassium hydroxide solution in $P$ to a mark just above the bulb. The pressure within the distributor, manometer, and burette is balanced against that in the compensator [5], the volume of gas in the burette is recorded, and the temperature of the water bath surrounding the compensator and burette is noted.

The sample to be analyzed is placed in the reaction vessel $D$, which has a capacity of approximately $70 \mathrm{ml}$. Obviously, the size of the sample to be used will depend on its amino-nitrogen content and the capacity of the burette. If the material to be analyzed is watersoluble, $10 \mathrm{ml}$ of the solution is taken. If the material is insoluble, a known weight is placed in the reaction flask and thoroughly wet out with $10 \mathrm{ml}$ of water saturated with carbon dioxide. The groundglass joint of the reaction vessel is properly greased [5], placed in position, and securely fastened with rubber bands. The air in the reaction vessel is swept out with pure carbon dioxide, which enters through stopcock $A$, and passes through a bubbling tube $A^{1}$ for the purpose of regulating the flow of carbon dioxide, and finally out at $F$. Ten minutes is usually ample time for removal of the air and, after this time, a sample of gas may be taken through the apparatus by the following procedure, to determine whether all of the air has been removed. The stopcocks are set so that the gas may pass from $D$ to $M$, a $500-\mathrm{ml}$ sample of carbon dioxide is taken into bulb $M$ through $A B D G K$, and stopcock $B$ is closed. The gas in $M$ is then passed to

\footnotetext{
3 Solutions were saturated with nitrogen at atmospheric pressure.
} 
the bulb $P$ through $K, G, H$, and $N$. The capillary from $K$ to $N$ is then swept out with nitrogen from the burette through SRQKGHN to the bulb $P$. Practically all of the carbon dioxide is immediately taken up by the solution of potassium hydroxide. The last traces of carbon dioxide are removed by repeated passing of the gas from $P$ into the bubbling pipette $J$, and back to $P$, three such passages being sufficient to remove measurable amounts of carbon dioxide. During analyses, oxides of nitrogen are formed from the spontaneous decomposition of the nitrous acid. These are removed by the alkaline permanganate solution in $\mathcal{J}$, five of the passages described above being used. The residual gas, which is nitrogen, is then taken into the burette. The burette is opened to the manometer, the pressure within the distributor and the burette adjusted to the pressure of the compensator [5], the temperature of the water bath noted, and the increase in volume of nitrogen is determined. As a check the gas in the burette is again passed through the potassium permanganate and potassium hydroxide solutions and the volume again determined.

The procedure outlined above is followed for a regular analysis. Since the rate of reaction is markedly affected by temperature, all experiments were done in a constant-temperature room at $22^{\circ} \mathrm{C}$. The nitrous acid solution, the preparation of which is described later, is added to the sample through $C^{1}$ by opening $D$ to bulb $P$ and slightly lowering the level of the solution in $P$. The measurement of the amount of gas evolved at any time is accomplished as follows. One and one-half minutes before taking a sample of gas, a partial vacuum is created in the reaction flask by lowering the leveling bulb $P^{1}$. The reaction flask $D$, which is attached to the distributor by means of rubber connections, is shaken for an arbitrary [4] but definite time ( 45 seconds in this work). A $500-\mathrm{ml}$ sample of gas is then taken by passing carbon dioxide through $D$ until $M$ is filled, and the amount of nitrogen is determined as previously described. The sampling, purification, and determination of the volume of the residual gas require approximately 7 minutes.

\section{RESULTS AND DISCUSSION}

\section{DECOMPOSITION OF NITROUS ACID}

As was previously pointed out [4], one of the possible sources of error in the Van Slyke method is the correction for relatively large amounts of nitrogen which may be evolved by the spontaneous decomposition of the nitrous acid. It was shown that the size of the blank depends on the age of the sodium nitrite solution, on the amount of mechanical action, and on the nature of the material being analyzed. Since the amount of free-amino nitrogen is often very small, it was particularly desirable to keep the blank corrections as small as possible.

A preliminary investigation indicated that in addition to the abovementioned factors, the size of the blank increases considerably with decreasing $\mathrm{pH}$ of the solution. Furthermore when the $\mathrm{pH}$ of the solution of nitrous acid was increased, there was a decrease in the rate at which nitrogen was evolved from an amino compound. As a result, it was necessary to seek those conditions which would give a sufficiently rapid evolution of nitrogen and as small a blank as possible. 
Sodium acetate, because of its bufiering action, was found to be very effective in decreasing the size of the blanks. Raising the $\mathrm{pH}$ of the nitrous acid solution from $\mathrm{pH} 3.4$ to $\mathrm{pH} 4$ by the addition of suitable amounts of sodium acetate decreased the blank by approximately 80 percent. In order to study the effect of sodium acetate on the rate of evolution of amino nitrogen, the experiments recorded in table 1 were performed. The results show that of the combinations of nitrous acid and sodium acetate tried, that given in experiment 7 was the most effective.

The nitrous acid solution used in subsequent experiments was prepared as follows. Five $\mathrm{ml}$ of glacial acetic acid was mixed with $5 \mathrm{ml}$ of a saturated solution of sodium acetate. Six grams of sodium nitrite was dissolved in $20 \mathrm{ml}$ of water previously saturated with $\mathrm{CO}_{2}$, the two solutions were mixed, gently stirred, and then poured into the funnel $C^{\prime}$. Exactly $1 \frac{11}{2}$ minutes after mixing the two solutions, the solution is allowed to run into the reaction vessel $D$, as previously described.

TABLE 1.-Rates of evolution of nitrogen from alanine in solutions in which the proportion of nitrous acid and sodium acetate were varied

\begin{tabular}{|c|c|c|c|c|c|c|}
\hline Experiment & $\begin{array}{l}\text { Glacial } \\
\text { acetic } \\
\text { acid }\end{array}$ & $\begin{array}{l}\text { Sodium } \\
\text { nitrite }\end{array}$ & $\begin{array}{l}\text { Saturated } \\
\text { sodium } \\
\text { acetate b }\end{array}$ & Water 。 & Time & $\begin{array}{l}\text { Total } N \\
\text { as amino } \\
\text { nitrogen }\end{array}$ \\
\hline & $\mathrm{ml}$ & $\mathrm{g}$ & $\mathrm{ml}$ & $\mathrm{ml}$ & $\min$ & Percent \\
\hline $1 \ldots . .$. & 3 & 12 & 10 & 30 & & $\begin{array}{r}81.2 \\
84.4\end{array}$ \\
\hline $2 \ldots$ & 5 & 12 & 10 & 25 & & $\begin{array}{l}92.8 \\
97.8\end{array}$ \\
\hline $3^{2} \ldots$ & 5 & 12 & 10 & 25 & $\begin{array}{l}15 \\
30\end{array}$ & $\begin{array}{l}69.4 \\
85.4\end{array}$ \\
\hline $4 \ldots$ & 5 & 6 & 10 & 25 & $\begin{array}{l}15 \\
30\end{array}$ & $\begin{array}{l}93.7 \\
97 . \theta\end{array}$ \\
\hline $5 \ldots$ & 2.5 & 3 & 10 & 25 & $\begin{array}{l}15 \\
30\end{array}$ & $\begin{array}{l}58.8 \\
84.3\end{array}$ \\
\hline $6 \ldots$ & 2.5 & 3 & & 35 & $\begin{array}{l}15 \\
30\end{array}$ & $\begin{array}{l}92.8 \\
99.1\end{array}$ \\
\hline 7 & 5 & 6 & 5 & 30 & 30 & 101 \\
\hline $8 \ldots$ & 5 & 6 & & 35 & $\begin{array}{l}30 \\
45\end{array}$ & $\begin{array}{l}101 \\
101\end{array}$ \\
\hline
\end{tabular}

s Reaction flask not shaken before sampling.

b Saturated aqueous solution at $22^{\circ} \mathrm{C}$.

- Volume given includes $10 \mathrm{ml}$ in which alanine was dissolved.

\section{ESTIMATION OF AMINO NITROGEN}

An examination of the literature pertaining to the Van Slyke method and its limitations $[1,2,3]$ shows that many amino acids, peptides, and related compounds give faulty values when analyzed for amino-nitrogen content. A confirmation of some of those findings was obtained during the present work with various amino acids. In view of such abnormalities, it would appear at first sight to be a discouraging task to attempt to estimate the amino-nitrogen content of an insoluble protein. Although exact mechanisms to account for the abnormal behavior of many compounds are not known, it is quite certain that in most cases, the extra nitrogen is not formed by the reaction of nitrous acid with the expected end-product of the reaction [3]. The complexity of the reactions suggests that the 
extra nitrogen might be formed by a series of reactions, probably involving more than one intermediate product. From this standpoint, it appears possible that insoluble proteins may be less abnormal than the less complex soluble compounds which are free to move about in solution and enter into a number of different reactions.

Of the various amino acids which give high values for amino nitrogen, only tryptophane and arginine evolve nitrogen at an appreciable rate during their secondary reactions. The remaining amino acids exhibit a rapid primary evolution of nitrogen which gives values over 100 percent, based on the theoretical content of amino nitrogen, in 5 minutes or less. They may or may not exhibit a very small increase in the amount of nitrogen evolved after this time. Since wool and collagen contain little if any tryptophane but relatively large amounts of arginine, an attempt was made in a previous investigation [4] to relate the arginine content of the protein to the rate of evolution of nitrogen during the secondary reaction.

The reaction of arginine with nitrous acid was reinvestigated with the new apparatus. Some preliminary results are shown in figures 2 and 3. Assuming that all of the nitrogen evolved (other than that corrected for in the blank) comes from the arginine, the curve in figure 2 shows that nearly 90 percent of the total nitrogen of arginine is liberated in about 150 hours. A closer examination of the first part of the curve, as shown in figure 3 , reveals that a rapid evolution of nitrogen, which is called the primary reaction, occurs in the first few minutes, followed by a much slower secondary reaction in which the rate of evolution of nitrogen is approximately constant. Extrapolation of the secondary portion of the curve (fig. 3) to zero time gives a value of 25 percent, which is equal to the $\alpha$-amino-nitrogen content of arginine. When the concentration of arginine in the reaction mixture was varied, as shown in table 2, the experimental values for the $\alpha$-amino-nitrogen content, obtained by extrapolation of the secondary portions of the curves, are in very good agreement with the theoretical values. It is also of interest to note that for the given concentration of nitrous acid the slopes of the curves (and the rate of evolution of nitrogen) are directly proportional to the initial concentrations of arginine. However, when the arginine content is kept constant and the concentration of nitrous acid is cut to half the usual value, the rate of evolution of nitrogen in the secondary reaction is very much lower, although the extrapolated value for amino nitrogen is the same.

In the previous investigation [4] it was suggested that the arginine content of an insoluble protein could be estimated by determining the relative rates of evolution of nitrogen from the guanidine nuclei in a protein and in arginine. If this is true, then the decrease in rate of evolution of nitrogen from a protein during the secondary reaction, with decrease in concentration of nitrous acid, should be proportional to the decrease in the rate of evolution of nitrogen from arginine under similar conditions. That this suggestion is not valid is shown in table 3 . The results indicate that the agreement between the calculated values for the arginine contents of wool and collagen and those obtained by isolation methods was the result of chance coincidence. 


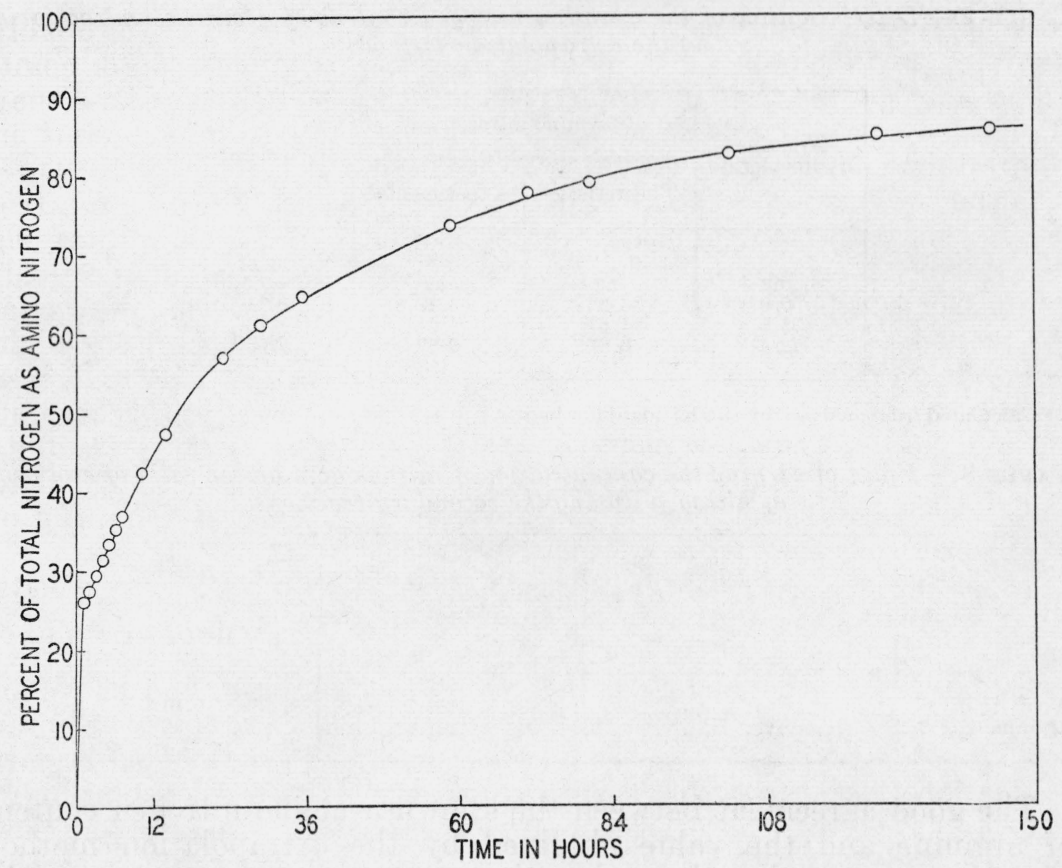

FIGURE 2.-Rate of evolution of nitrogen during the continued treatment of arginine with nitrous acid.

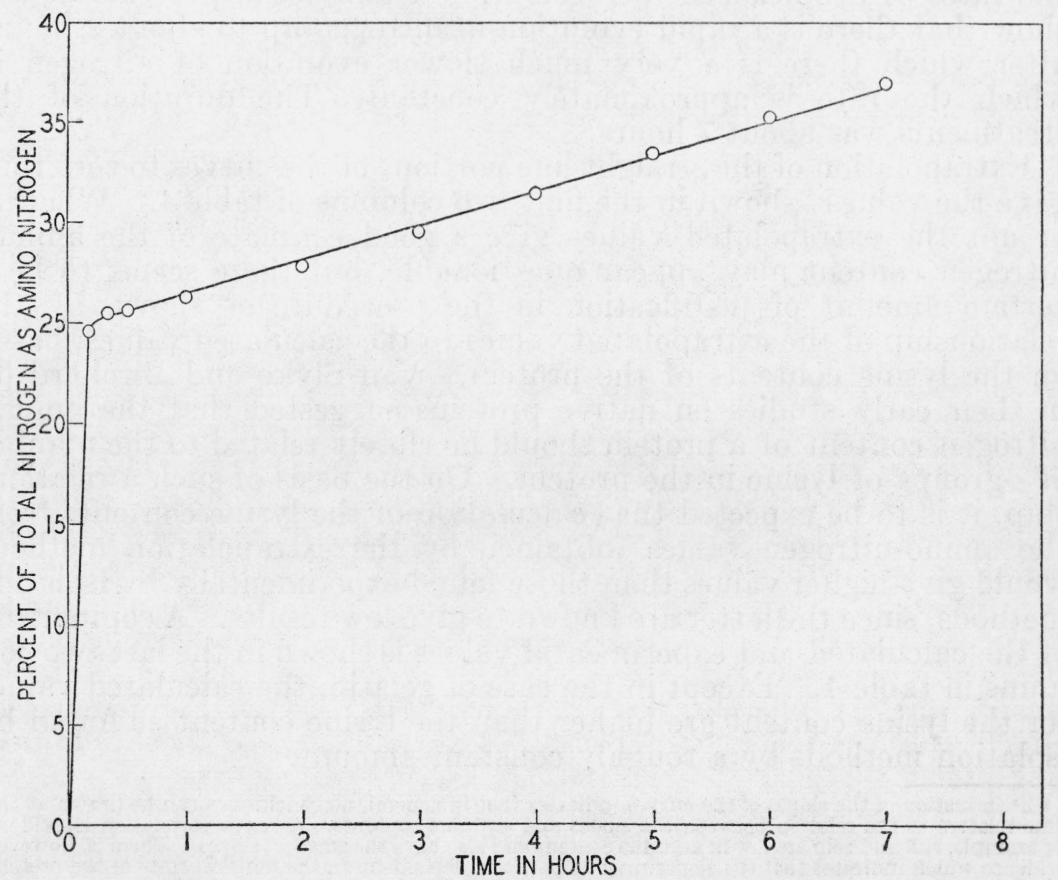

FIGURE 3.-Rate of evolution of nitrogen from arginine.

This is the initial portion of the curve shown in figure 2 plotted on a larger scale. 
TABLE 2.-Determination of the a-amino-nitrogen content of arginine hydrochloride by the extrapolation method.

\begin{tabular}{|c|c|c|c|}
\hline \multirow{2}{*}{$\begin{array}{c}\text { Arginine } \\
\text { hydrochloride }\end{array}$} & \multicolumn{2}{|c|}{ Amino nitrogen } & \multirow{2}{*}{ Slope of curve } \\
\cline { 2 - 4 } & Theoretical s & Experimental & \\
\hline & & & \\
$\mathrm{mg}$ & $\mathrm{mg}$ & $\mathrm{mg}$ & $\mathrm{mg}$ of \\
nitrogen/hr \\
50.0 & 3.22 & 3.17 & 0.24 \\
25.1 & 1.63 & 1.64 & .13 \\
12.5 & 0.81 & 0.82 & .06 \\
\hline
\end{tabular}

a Calculated from analyses by the Kjeldahl method.

TABLE 3.-Effect of varying the concentration of nitrous acid on the rates of evolution of nitrogen during the secondary reactions

\begin{tabular}{l|r|r}
\hline & \multicolumn{2}{|c}{ slope } \\
\cline { 2 - 4 } & $2.1 \mathrm{M} \mathrm{HNO}_{2}$ & $1.05 \mathrm{M} \mathrm{HNO}_{2}$ \\
\hline Wool & 0.16 & 0.13 \\
Arginine & 1.86 & .36 \\
\hline
\end{tabular}

The good agreement between the known $\alpha$-amino-nitrogen content of arginine and the value obtained by the extrapolation method (fig. 3) suggested that the amino-nitrogen content of a protein might also be estimated by that method. The results of determinations of the rates of evolution of nitrogen from a number of proteins (fig. 4) show that there is a rapid evolution of nitrogen up to about 2 hours, after which there is a very much slower evolution of nitrogen in which the rate is approximately constant. The duration of the treatments was about 7 hours.

Extrapolation of the straight line portions of the curves to zero time gave the values ${ }^{4}$ shown in the first two columns of table 4 . Whether or not the extrapolated values give a good estimate of the aminonitrogen content may appear questionable, but there seems to be a certain amount of justification in the procedure as shown by the relationship of the extrapolated values to the calculated values, based on the lysine contents of the protein. Van Slyke and Birchard [6] in their early studies on native proteins suggested that the aminonitrogen content of a protein should be closely related to the number of $\epsilon$-groups of lysine in the protein. On the basis of such a relationship, it is to be expected that calculation of the lysine contents from the amino-nitrogen values (obtained by the extrapolation method) would give higher values than those found experimentally by isolation methods, since the latter are known to give low results. A comparison of the calculated and experimental values is shown in the last two columns in table 4. Except in the case of gelatin, the calculated values for the lysine content are higher than the lysine content as found by isolation methods by a roughly constant amount.

\footnotetext{
1 Examination of the slopes of the curves indicates that in general, no conclusions can be drawn at this time relative to the relation between the slopes and arginine contents. A rough correlation is evident: for example, silk and zein are low in arginine content and also have the smallest slopes. There is, however, evidence which indicates that the slopes may be partially dependent on the physical state of the protein. Further work is in progress.
} 


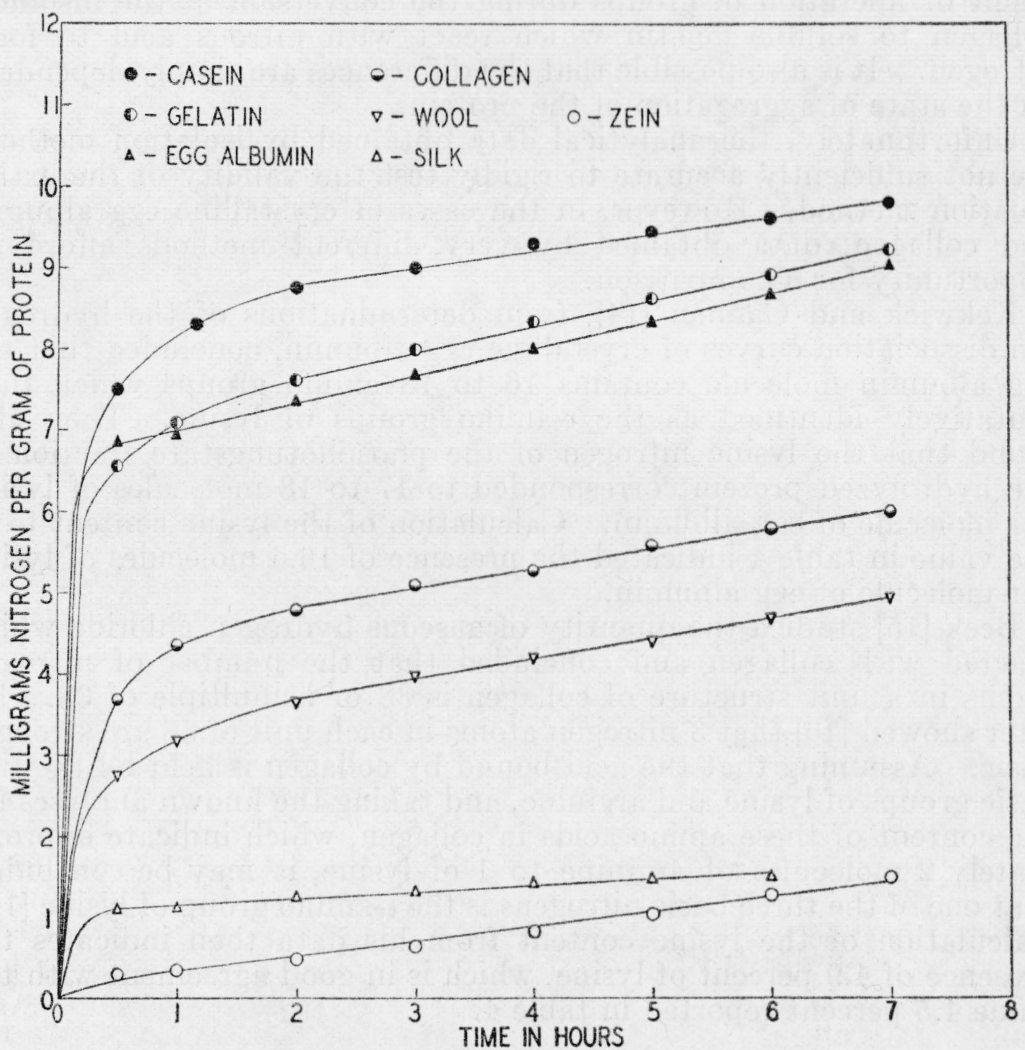

FIgURE 4.-Rates of evolution of nitrogen from various proteins.

Although collagen and gelatin are presumably the same protein (the gelatin was prepared from a sample of the collagen used for these analyses), they give different values for amino nitrogen by the extrapolation method. The higher value obtained for gelatin may be the

TABLE 4.-Free a mino-nitrogen content of various proteins as obtained by the extrapolation method

[The values for lysine in the last two columns represent those calculated from the amino-nitrogen contents and those recorded in the literature as obtained by isolation methods.]

\begin{tabular}{|c|c|c|c|c|}
\hline \multirow[b]{2}{*}{ Protein } & \multicolumn{2}{|c|}{ Free amino-nitrogen } & \multicolumn{2}{|c|}{ Lysine } \\
\hline & $\%$ of total & $\begin{array}{l}\mathrm{mg} \text { of } \mathrm{N} / \mathrm{gm} \\
\text { of protein }\end{array}$ & Calculated & Literature \\
\hline Zein... & 0.08 & 0.12 & ${ }_{0.12}$ & $\begin{array}{l}\% \\
0.0\end{array}$ \\
\hline Silk ............. & .56 & 1.05 & 1.10 & $\left.\begin{array}{ll}0.25 & 8 \\
0.85 & 9\end{array}\right]$ \\
\hline $\begin{array}{l}\text { Wool } \\
\text { Collagen } \\
\text { Egg albumin. }\end{array}$ & $\begin{array}{l}1.94 \\
2.37 \\
4.50\end{array}$ & $\begin{array}{l}3.16 \\
4.26 \\
6.75\end{array}$ & $\begin{array}{l}3.3 \\
4.5 \\
7.1\end{array}$ & $\begin{array}{l}2.3 \\
2.75[10] \\
4.97[12]\end{array}$ \\
\hline $\begin{array}{l}\text { Gelatin } \\
\text { Casein }\end{array}$ & $\begin{array}{l}4.67 \\
5.68\end{array}$ & $\begin{array}{l}7.03 \\
8.36\end{array}$ & $\begin{array}{l}7.3 \\
8.7\end{array}$ & $\begin{array}{l}2.75[11] \\
6.5[13]\end{array}$ \\
\hline
\end{tabular}


result of liberation of groups during the conversion of the insoluble collagen to soluble gelatin which react with nitrous acid to form nitrogen. It is also possible that the differences are simply dependent on the state of aggregation of the protein.

Unfortunately, the analytical data obtained by isolation methods are not sufficiently accurate to rigidly test the validity of the extrapolation method. However, in the cases of crystalline egg albumin and collagen, data obtained by very different methods afford an opportunity for a comparison.

Kekwick and Cannan [14], from determinations of the hydrogen ion dissociation curves of crystalline egg albumin, concluded that the egg albumin molecule contains 16 to 18 amino groups which they tentatively identified as the $\epsilon$-amino groups of lysine. They also found that the lysine nitrogen of the phosphotungstate fraction of the hydrolyzed protein corresponded to 17 to 18 molecules of lysine per molecule of egg albumin. Calculation of the lysine content from the value in table 4 indicated the presence of 16.6 molecules of lysine per molecule of egg albumin.

Beek [15] studied the quantity of gaseous hydrogen chloride which reacted with collagen and concluded that the number of nitrogen atoms in a unit structure of collagen is 38 or a multiple of 38 . $\mathrm{He}$ later showed [16] that 3 nitrogen atoms in each unit of 38 are strongly basic. Assuming that the acid bound by collagen is held by the free basic groups of lysine and arginine, and taking the known analyses for the content of these amino acids in collagen, which indicate approximately 2 molecules of arginine to 1 of lysine, it may be concluded that one of the three basic nitrogens is the $\epsilon$-amino group of lysine [17]. Calculation of the lysine content from his data then indicates the presence of 4.9 percent of lysine, which is in good agreement with the value 4.5 percent reported in table 4 .

\section{SUMMARY}

An apparatus for determining the rate of evolution of nitrogen from proteins and other amino compounds during treatment with nitrous acid is described. Examination of the rate curves of a number of proteins indicates that there is a primary reaction with a relatively rapid evolution of nitrogen, followed by a secondary reaction with a much slower evolution of nitrogen in which the rate is approximately constant. Extrapolation of the straight line portions of the curves to zero time gives values which appear to be good estimates of the aminonitrogen contents of the proteins. In the case of crystalline egg albumin and collagen, the extrapolated values are in good agreement with values obtained by other methods. No conclusions relative to the significance of the slopes of the curves are drawn at this time.

The authors are indebted to Martin Shepherd for assistance in designing the apparatus used in this work and for many helpful suggestions relative to its operation. 


\section{REFERENCES}

[1] J. Biol. Chem. 9, 185 (1911); 12, 275 (1912).

[2] Proc. Roy. Soc. [B] 115, 142 (1934).

[3] J. Biol. Chem. 82, 587 (1929).

[4] J. Research NBS 14, 563 (1935) RP787.

[5] B. S. J. Research 6, 121 (1931) RP266.

[6] J. Biol. Chem. 16, 539 (?).

[7] Am. J. Physiol. 1\%, 231 (1906).

[8] J. Biol. Chem. 93, 105 (1931).

[9] Z. physiol. Chem. 120, 207 (1922).

[10] J. Biol. Chem. 86, 107 (1930).

[11] Z. physiol. Chem. 35, 70 (1902).

[12] Biochem. J. 26, 1101 (1932).

[13] J. Biol. Chem. 105, 667 (1934).

[14] Biochem. J. 30, 235 (1934).

[15] BS J. Research 8, 549 (1932) RP434.

[16] J. Research NBS, 14, 217 (1935) RP765.

[17] Personal communication from J. Beek, Jr. Results to be published.

Washington, July 6, 1937. 